\title{
Structure-Function Relationship of a Gellan Family of Polysaccharide, S-198 Gum, Produced by Alcaligenes ATCC31853
}

\author{
Masakuni Tako ${ }^{1,2 *}$, Seiko kitajima ${ }^{1}$, Takuya Yogi ${ }^{1}$, Keiko Uechi', Masayuki Onaga ${ }^{1}$, \\ Yukihiro Tamaki ${ }^{1}$, Shuntoku Uechi ${ }^{1}$ \\ ${ }^{1}$ Department of Subtropical Bioscience and Biotechnology, University of the Ryukyus, Okinawa, Japan \\ ${ }^{2}$ Health and Longevity Research Laboratory, Integrated Innovation Research Center, University of the Ryukyus, \\ Okinawa, Japan \\ Email: "tako@eve.u-ryukyu.ac.jp
}

Received 3 February 2016; accepted 23 May 2016; published 26 May 2016

Copyright (C) 2016 by authors and Scientific Research Publishing Inc.

This work is licensed under the Creative Commons Attribution International License (CC BY). http://creativecommons.org/licenses/by/4.0/

(c) (i) Open Access

\section{Abstract}

The structure-function relationship of a gellan family of polysaccharides, S-198 gum produced by Alcaligenes ATCC31853 was investigated in terms of rheological aspects. The flow curves of S-198 gum showed plastic behavior above $0.3 \%$. Gelation did not occur in S-198 gum solution at low temperature $\left(0^{\circ} \mathrm{C}\right)$, even at $0.8 \%$. Both the viscosity and the elastic modulus remained constant with increasing temperature up to $80^{\circ} \mathrm{C}$. The elastic modulus decreased a little with the addition of $\mathrm{CaCl}_{2}(6.8 \mathrm{mM})$, but then once again remained constant up to $80^{\circ} \mathrm{C}$. The highest elastic modulus was observed for deacylated gellan gum with the addition of $\mathrm{CaCl}_{2}$ and increased slightly with increasing temperature up to $80^{\circ} \mathrm{C}$, which was considered to be a transition temperature, after which it decreased rapidly. The elastic modulus of S-198 gum in the presence of urea (4.0 M) was lower than that in aqueous solution at low temperature $\left(0^{\circ} \mathrm{C}\right)$, but remained constant with increasing temperature up to $80^{\circ} \mathrm{C}$. The intramolecular associations, (hydrogen bonding and van der Waals forces of attraction), of $S-198$ gum molecules in aqueous solutions were proposed. The gellan family of polysaccharides, S-198, S-88, S-657, rhamsan, welan and gellan gum, provided a good opportunity to investigate the structure-function relationship for polysaccharides.

\section{Keywords}

S-198 Gum, Alcaligenes ATCC31853, Thermal Stability, Intramolecular Associations, Gellan Family of Polysaccharide

\footnotetext{
${ }^{*}$ Corresponding author.
}

How to cite this paper: Tako, M., kitajima, S., Yogi, T., Uechi, K., Onaga, M., Tamaki, Y. and Uechi, S. (2016) Structure-Function Relationship of a Gellan Family of Polysaccharide, S-198 Gum, Produced by Alcaligenes ATCC31853. Advances in Biological Chemistry, 6, 55-69. http://doi.org/10.4236/abc.2016.63007 


\section{Introduction}

Polysaccharides produce commercially from seaweeds, plants, animals and micro-organisms that have been used in food and non-food (cosmetic, paper, textile, paint, oil, pharmaceutical, and medical) industries as gelling, stabilizing, emulsifying, oil-drilling, coating, encapsulating, flocculating, swelling, film-forming, membraneforming, and protective agents. Specifically, for several decades, attention has been directed to polysaccharide gels. We have previously investigated the molecular origin of their rheological characteristics and have proposed gelation mechanisms for $\boldsymbol{k}$-carrageenan [1] [2], $\boldsymbol{l}$-carrageenan [3], agarose (agar) [4], gellan gum [5] [6], amylose [7] [8], curdlan [9], alginic acid [10] [11] and deacetylated rhamsan gum [12] at the molecular level in aqueous solutions.

Xanthan gum, a bacterial polysaccharide, has curious rheological characteristics [13]-[18] and gelation occurred after mixing it with galactomannan and glucomannan. We proposed a synergistic co-gelation mechanism for a mixture of solutions of xanthan and galactomannan (locust-bean gum [19]-[21], guar gum [22], tara-bean gum [23], Leucaena gum [24], and Leonix gum [25]), and konjac glucomannan [26] [27], in which trisaccharide side-chains of the former molecules participate in the interaction. The interaction between the extracellular bacterial polysaccharide xanthan produced by Xanthomonas campestris and typical galactomannan and glucomannan components of the plant cell wall may play a role in the host-pathogen relationship, because $X$. campestris is a bacterial plant pathogen. Furthermore, the mode of the intermolecular interaction may demonstrate the existence of D-mannose-specific binding sites in several cell recognition processes. Synergistic interactions with galactomannan and $\kappa$-carrageenan [2] [28], and with agarose [29] have also been reported. Recently, we proposed gelatinization and retrogradation mechanisms for rice [30]-[32], potato [33] and wheat [34] [35] starches. The short side-chains of rice, potato and wheat amylopectin molecules may participate in the intermolecular hydrogen bonding with amylose molecules. Consequently, we have discovered some basic rules for the gel-formation processes of the polysaccharides in aqueous solutions. The gelation occurs in the formation of intra- and intermolecular associations, where hemiacetal oxygen, hydroxyl and/or methyl groups of the sugar residues of the polysaccharides contribute hydrogen bonding and/or van der Waals interactions in aqueous solutions. The sulfuric acid and carboxyl groups of the sugar residues of some acidic polysaccharides, such as $\kappa$-carrageenan, l-carrageenan, gellan gum, alginic acid and deacetylated rhamsan gum, also participate in intra- and/or intermolecular associations through univalent or divalent cations with ionic bonding and/or electrostatic forces of attraction. Based on such gelation mechanisms, we have also discussed the role of polysaccharides in gelation, gelatinization and retrogradation processes in water and have demonstrated the principle of polysaccharide gels [36] [37] and starch gelatinization and retrogradation [38].

Gellam gum is a bacterial polysaccharide produced by Sphingomonas elodea and has potential industrial applications as a gelling agent alternate to agarose (agar) and carrageenans in the food industry, medicine and biotechnology [39]-[42]. The primary structure of the polysaccharide consists of tetrasaccharide repeating units, 3)- $\beta$-D-Glcp-( $1 \rightarrow 4)-\beta$-D-GlcpA( $1 \rightarrow 4)-\beta$-D-Glcp-(1 $\rightarrow 4)-\alpha$-L-Rhap-(1 [43] [44]. The polysaccharide contains $O$ acetate and L-glycerate groups at C-6 and C-2 of -3)- $\beta$-D-Glcp-(1 [45]. Under suitable conditions, the native gellan gum [6] forms weak elastic gels, however, it forms stiff, brittle gels upon deacylation [5]. Physicochemical investigations of deacylated gellan gum have been conducted by many researchers [5] [46]-[50]. Chandrasekaran et al. reported that a tertiary structure of deacylated gellan gum consisted of two identical left-handed, three-fold double helices in the solid state, similar to that of agarose molecules [48].

We previously proposed a gelation mechanism for deacylated gellan gum in aqueous solution, as illustrated in Scheme 1 [5]. Intramolecular hydrogen bonding might occur between the $\mathrm{OH}-4$ group of the D-glucosyl residue and the adjacent hemiacetal oxygen atom of the L-rhamnosyl residue, and between $\mathrm{OH}-3$ of the D-glucosyl residue and the adjacent hemiacetal oxygen atom of the D-glucuronosyl residue, as in cellulose, to make the gellan gum molecule rigid. In turn, intermolecular association might occur between the methyl group and the hemiacetal oxygen atom of the L-rhamnosyl residues on different molecules based on van der Waals forces of attraction via the cage effect. In the presence of $\mathrm{CaCl}_{2}$, an intermolecular $\mathrm{Ca}^{2+}$ bridge, as in $l$-carrageenan [3] and alginic acid [10] [11], also occur in the form of ionic bonding between the carboxyl oxygen atom of the D-glucuronosyl residues on different molecules. The associations are very strong and stable even at high temperature range.

Lee and Chandrasekaran [49] reported that welan, rhamsnan and S-657 gum molecules formed half-staggered double helices stabilized by carboxylate-hydroxymethyl interaction with hydrogen bonding in the solid state, 
similarly to gellan gum molecules. We proposed possible intramolecular associations for welan (Scheme 2) [51], rhamsan (Scheme 3) [52] [53], and S-657 (Scheme 4) [54], the structures of which are similar to that of gellan gum with the following exceptions; substitution at O-3 of every D-glucosyl residue next to the D-glucuronosyl residue by either $\alpha$-L-rhamnosyl or $\alpha$-L-mannosyl side-chains in a 2:1 ratio for welan [55], substitution at C-6 of every D-glucosyl residue next to the L-rhamnosyl residue by $\alpha$-D-glucosyl disaccharide side-chains for rhamsan

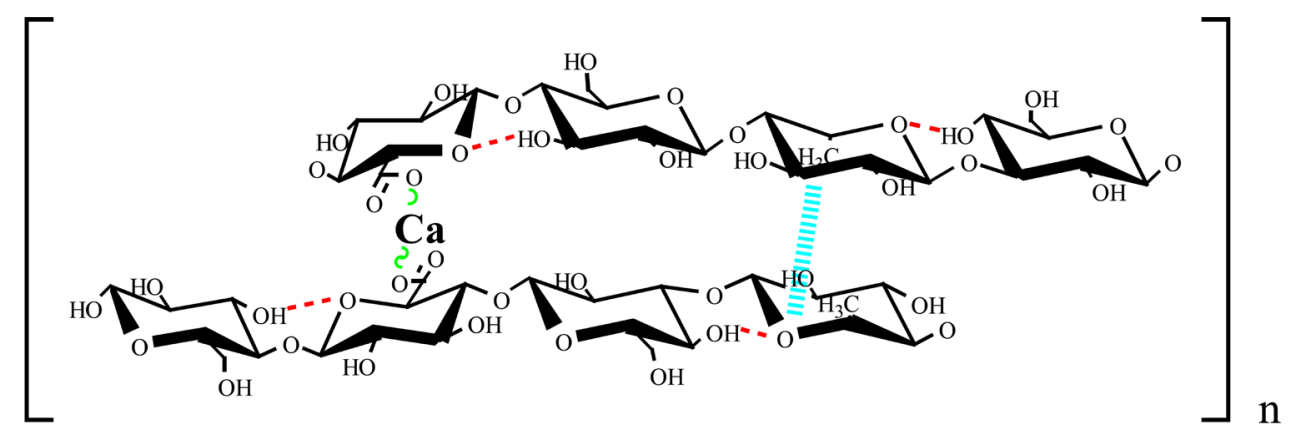

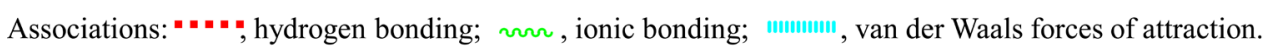
(Reproduced with permission from reference 37. Copyright 2015 Scientific Research Publishing.)

Scheme 1. Gelation mechanism of deacetylated gellan gum in aqueous solution.

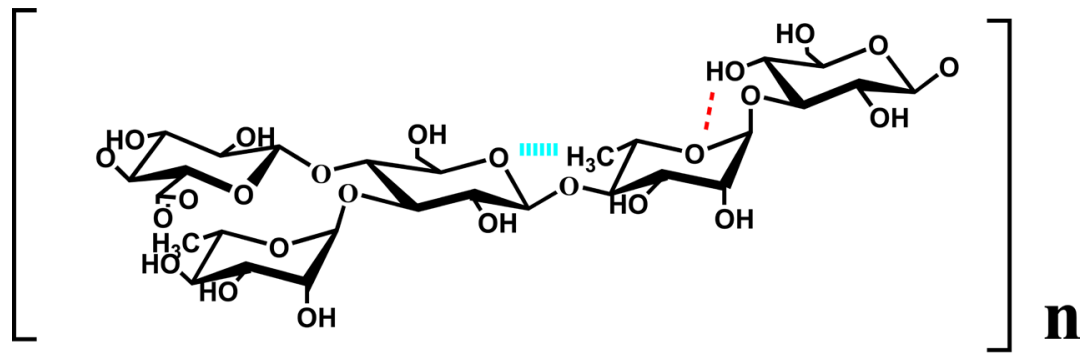

Associations; . . ..., hydrogen bonding; ‥แแ , van der Waals forces of attraction.

(Reproduced with permission from reference 37. Copyright 2015

Scientific Research Publishing.)

Scheme 2. Intramolecular associations of welan gum in aqueous solution.

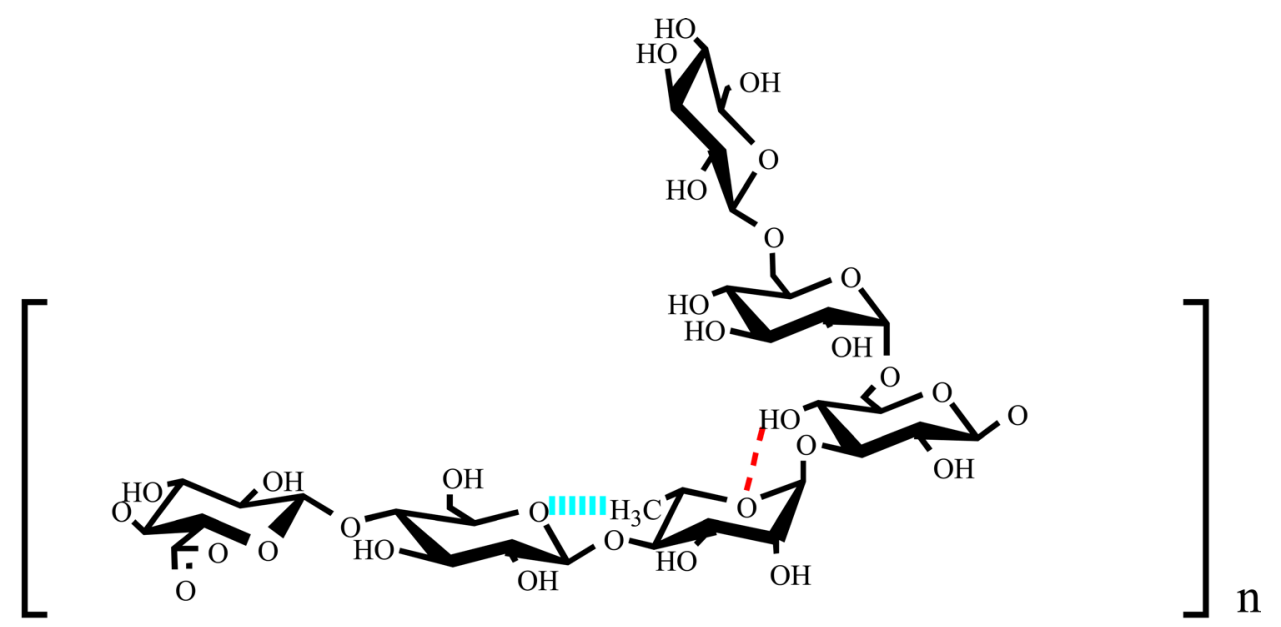

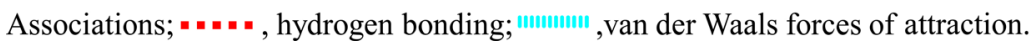

(Reproduced with permission from reference 37. Copyright 2015

Goientifie Researth Dublishings)

Scheme 3. Intramolecular associations of rhamsan gum in aqueous solution. 
[56], and substitution at O-3 of every D-glucosyl residue next to the D-glucuronosyl residue by $\alpha$-L-rhamnosyl disaccharide side-chains for S-657 gum [57]. The methyl groups of L-rhamnosyl residues played a dominant role in the thermal stability due to the formation of intramolecular van der Waals forces of attraction. The models proposed for welan (Scheme 2), rhamsan (Scheme 3) and S-657 (Scheme 4) gum corresponded to a single-stranded helix. We also demonstrated possible intramolecular associations of S-88 gum [58] which consist of 3)- $\beta$-D-Glcp-( $1 \rightarrow 4)-\beta$-D-GlcpA( $1 \rightarrow 4)-\beta$-D-Glcp-( $1 \rightarrow 4)$ - $\alpha$-L-Rhap-or-L-Manp-(1 where every D-glucosyl residue next to the D-glucuronosyl is substituted at O-3 by $\alpha$-L-rhamnosyl side-chains [59], as illustrated in Scheme 5. The S-88 gum also exhibits thermostable characteristics in terms of viscosity and elastic modulus in aqueous solutions. The thermal stability of the gellan family of polysaccharides, welan, rhamsan, S-657 and S-88 gums is essentially attributed to the intramolecular associations proposed.

Alhough rhamsan contains one $O$-acetyl group per repeating unit and has non-gelling properties, after deacetylation by alkaline treatment, it forms a gel [12]. This dramatic change is caused by the conformational change on the L-rhamnosyl residues from ${ }^{1} \mathrm{C}_{4}$ - to ${ }^{4} \mathrm{C}_{1}$-pyranose rings where the C-6 methyl group of the L-rhamnosyl residues on the main-chain shifted from an equatorial to an axial orientation, as confirmed by ${ }^{1} \mathrm{H}$-NMR spectroscopy [12]. We proposed a gelation mechanism for deacetylated rhamsan gum (Scheme 6) [12], in agreement with that of deacylated gellan gum, as mentioned above (Scheme 1) [5].
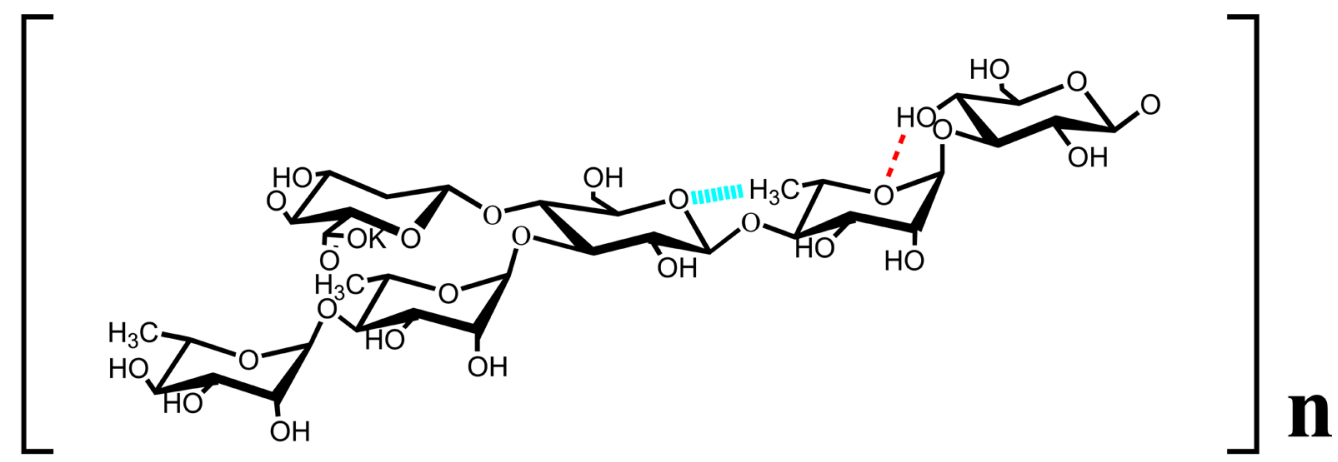

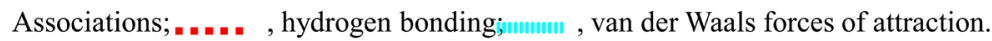

(Reproduced with permission from reference 37. Copyright 2015 Scientific Research Publishing.)

\section{Scheme 4. Intramolecular associations of S-657 gum in aqueous solution.}

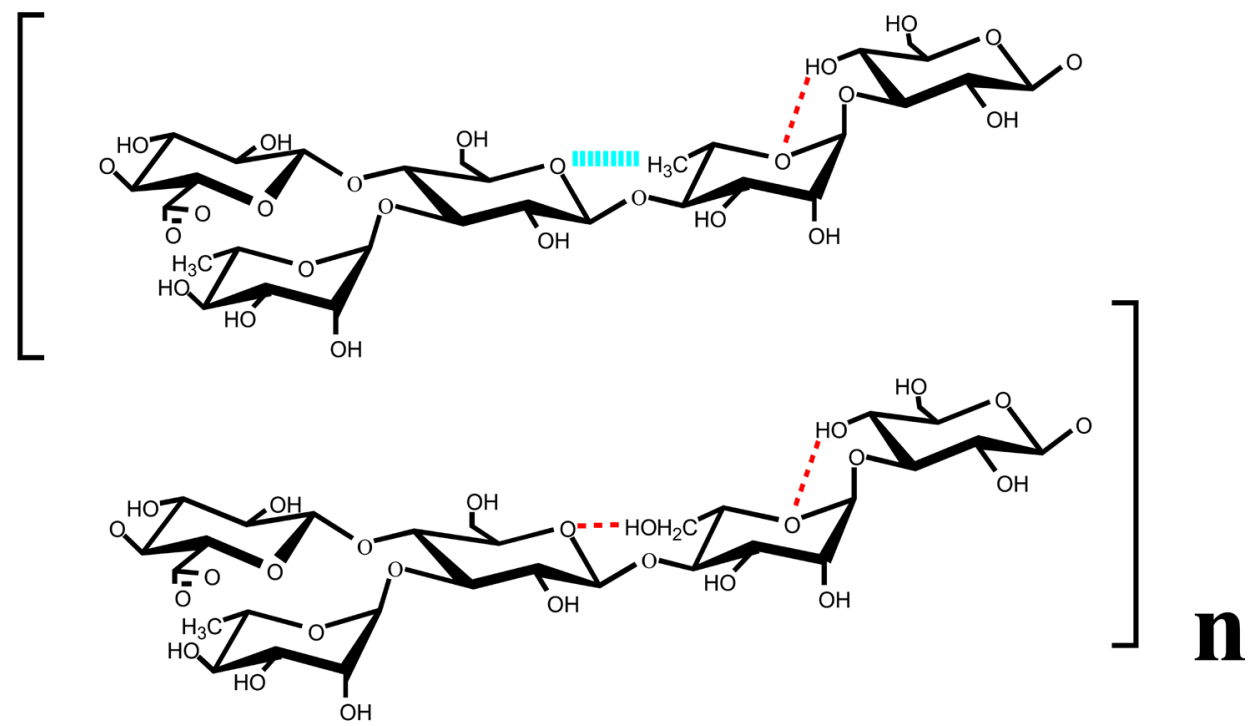

Associations; . . ... . , hydrogen bonding; ‥ии , van der Waals forces of attraction.

\footnotetext{
Scheme 5. Intramolecular associations of S-88 gum in aqueous solution.
} 


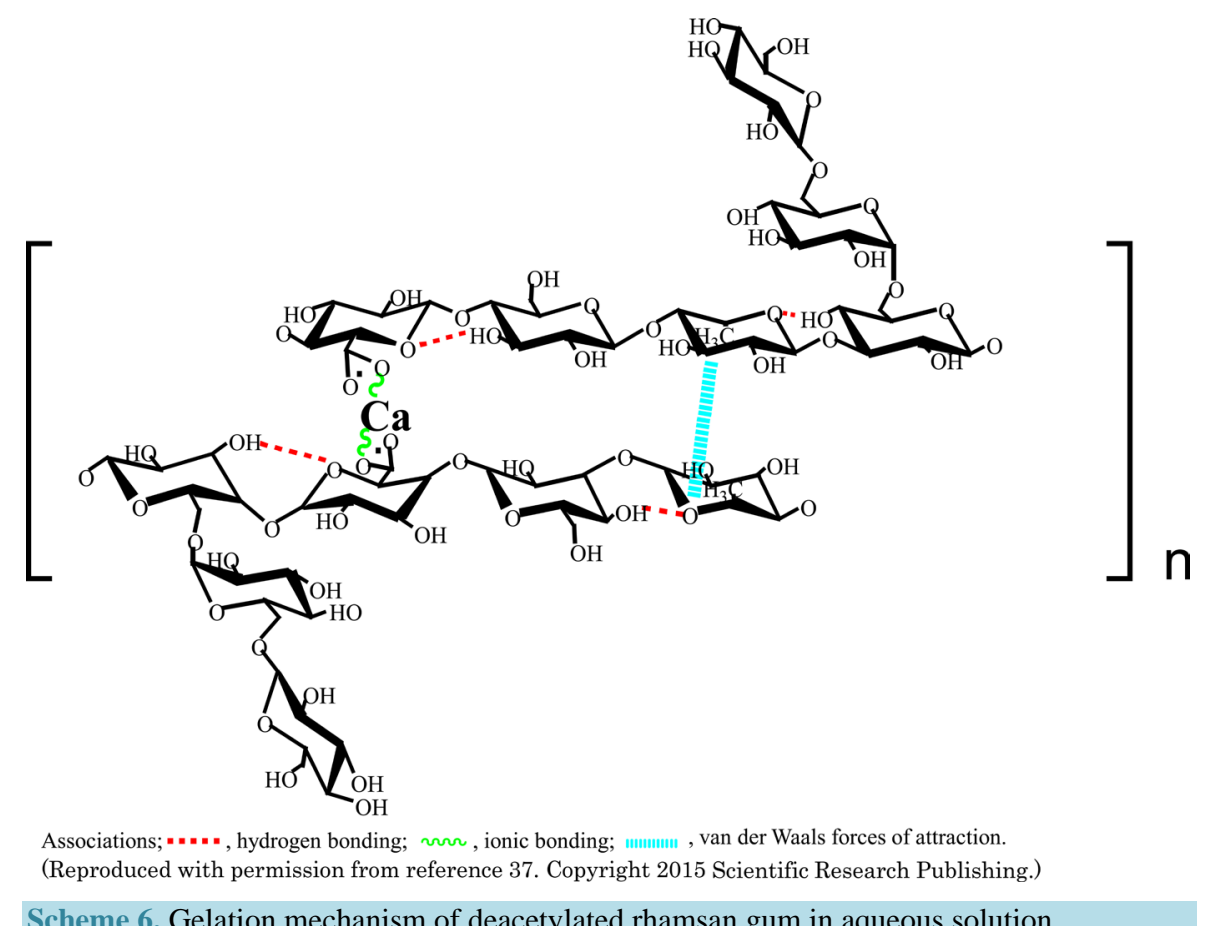

We previously discussed the molecular origin of the gelation characteristics of native gellan gum [6] which substituted acetyl groups at C-6 of the 3-linked D-glucose and L-glyceric acid groups at C-2 of the same residue. Thus, we proposed intra- and intermolecular associations of native gellan gum molecules in aqueous solution, as illustrated in Scheme 7. Intramolecular associations may occur between OH-4 group of the D-glucosyl residue and the adjacent hemiacetal oxygen atom of the L-rhamnosyl residue with hydrogen bonding, between $\mathrm{OH}-3$ of the D-glucosyl residue and the adjacent hemiacetal oxygen atom of the D-glucuronosyl residue with hydrogen bonding, and between the C-6 methyl group of the L-rhamnosyl residue, which adopts a ${ }^{1} \mathrm{C}_{4}$-pyranose-ring conformation, and the adjacent hemiacetal oxygen atom of the D-glucosyl residue with van der Waals forces of attraction to make the polymer molecules rigid. Intermolacular associations may occur between the C-6 methyl group, which adopts a ${ }^{4} \mathrm{C}_{1}$-pyranose ring conformation of the L-rhamnosyl residue and the counter hemiacetal oxygen atom of the L-rhamnosyl residue on different molecules in the form of van der Waals interactions via the cage effect. A slight increase in the $\tan \delta$ value with increasing concentration, however, indicates that a large number of intramolecular associations are involved within native gellan gum molecules, which may be attributed to the adoption of the ${ }^{1} \mathrm{C}_{4}$-pyranose ring conformation, as confirmed by ${ }^{1} \mathrm{H}$-NMR spectroscopy [6]. In the presence of $\mathrm{CaCl}_{2}$, an intermolecular $\mathrm{Ca}^{2+}$ bridge also forms as a result of ionic bonding between the carboxyl oxygen atoms of the D-glucuronosyl residues on different molecules. As reported previously [12], the L-rhamnosyl residues in some of the native rhamsan gum might adopt a ${ }^{1} \mathrm{C}_{4}$ pyranose ring conformation and convert to a ${ }^{4} \mathrm{C}_{1}$ pyranose ring conformation after deacetylation. This conformational change of the L-rhamnosyl residues contributed to the gel formation for deacetylated rhamsan gum [12]. Thus, the associations depicted in Scheme 7 provide explanations of not only the rheological characteristics of native and deacylated gellan gum, but also those of welan, native rhamsan, deacetylated rhamsan, S-657 and S-88 gum in aqueous solutions.

S-198 gum is a bacterial polysaccharide produced by Alcaligenes ATCC 31853. This gum is non-gel-forming and yields a thermostable, highly viscous solution even at high temperature [40]. The main chain of the polysaccharide consists of tetrasaccharride repeating units, 3)- $\beta$-D-Glp-( $1 \rightarrow 4)-\beta$-D-GlcpA( $1 \rightarrow 4)-\beta$-D-Glcp-( $1 \rightarrow 4)$ $\alpha$-L-Rhap-or-L-Manp-(1 as in S-88 gum, where the L-rhamnosyl side-chain is substituted at C-4 of every 3-linked D-glucosyl residue [60].

We report herein the non-Newtonian behavior and dynamic viscoelasticity of S-198 gum, and its rheological properties are analyzed with respect to its association characteristics and compared with those of the gellan family of polysaccharides, welan, rhamsan, S-657, S-88, deacetylated rhamsan and native gellan gum at the molecular level. 


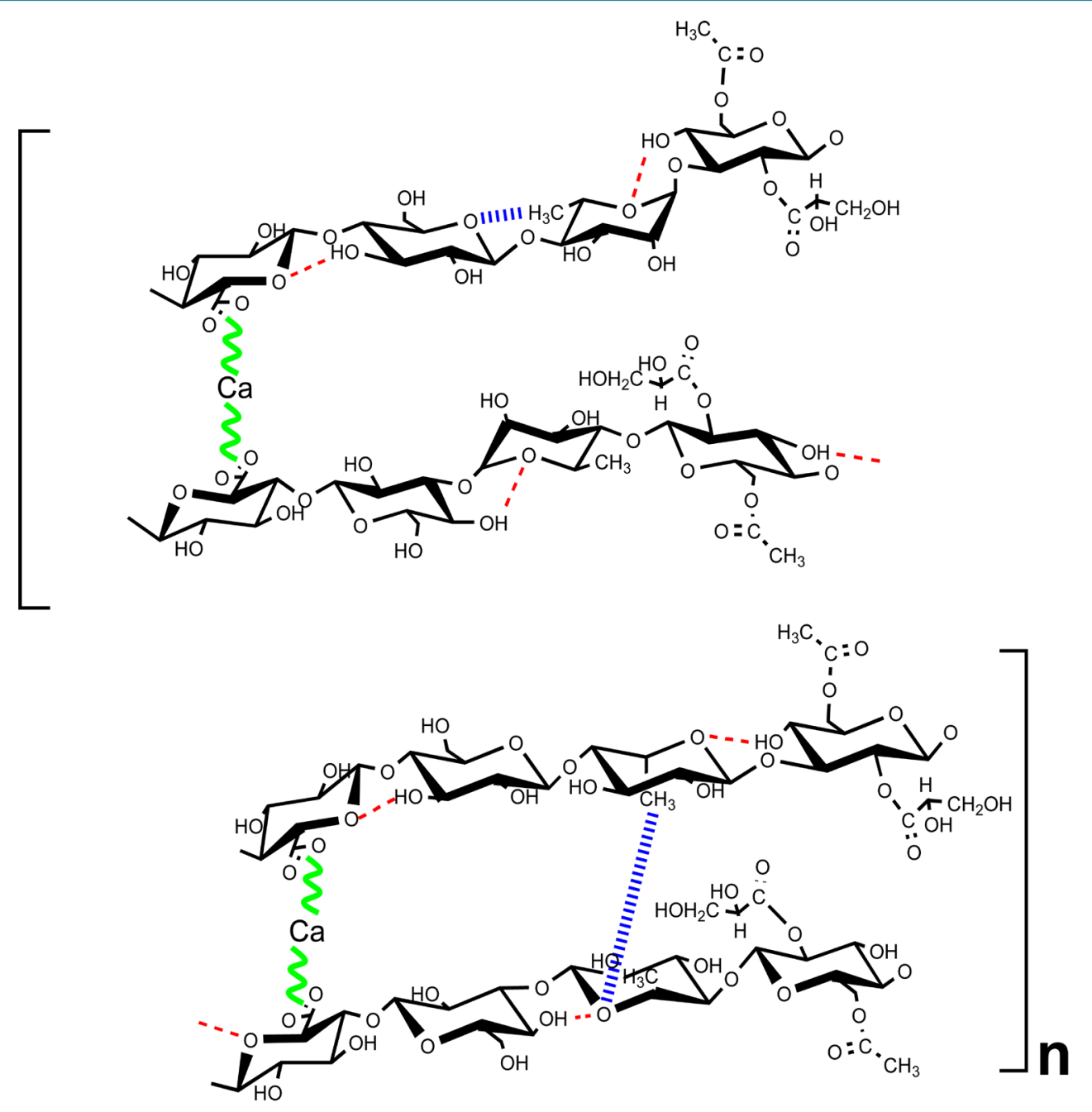

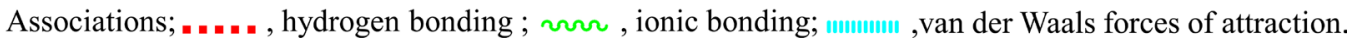

Scheme 7. Gelation mechanism of native gellan gum in aqueouss solution.

\section{Experimental}

\subsection{Materials}

S-198 gum was kindly supplied by CP-Kelco (CA, U.S.A.) and was dissolved in hot water $\left(90^{\circ} \mathrm{C}\right)$ as a $0.1 \%$ solution. The sample was prepared using the same methods as reported in previously, which are as follows: heated at $90^{\circ} \mathrm{C}$ for $20 \mathrm{~min}$, cooled at room temperature, centrifuged at 23,000 g for $1 \mathrm{~h}$, and filtered through Celite 545 (which had been pre-treated with boiling $3 \mathrm{M} \mathrm{HCl}$ for $30 \mathrm{~min}$ and washed with distilled water until reaching $\mathrm{pH}$ 6.0) [51]-[54] [58]. In the presence of $0.05 \% \mathrm{KCl}$, ethanol (2 vol.) was added to the filtrate and the precipitate was dried in vacuo. Purified S-198 gum was redissolved in hot water and the solution was deionized by passage through a column of Amberlite IR-120 $\left(\mathrm{H}^{+}\right)$, and neutralized with $0.1 \mathrm{M} \mathrm{KOH}$. The solution was filtered through Celite 545 once more. Ethanol (2 vols.) was added to the filtrate in the presence of $0.05 \% \mathrm{KCl}$, and the precipitate was dried in vacuo.

Gellan, welan, rhamsan, S-657 and S-88 gum were also supplied by CP-Kelco (CA, U.S.A.) and were dissolved in hot water $\left(90^{\circ} \mathrm{C}\right)$ as a $0.1 \%$ solution. The samples were prepared using the same methods as described above.

\subsection{Viscosity and Dynamic Viscoelasticity Measurements}

The viscosities at various shear rates $\left(1.19-95.05 \mathrm{~s}^{-1}\right)$ and the dynamic viscoelasticity at a steady angular veloc- 
ity (3.77 rad/s) were measured using a rheogoniometer equipped with a coaxial cylinder (18 mm diam.) and a rotating outer cylinder (22 mm diam., 60 mm long) (IR-103, Iwamoto Seisakusho Co., Ltd., Japan). Circulating oil from a Thermo-cool (LCH-130F, Toyo Co., Ltd., Japan) controlled the temperature from $0^{\circ} \mathrm{C}$ to $90^{\circ} \mathrm{C}$, and increased it at a rate of $1^{\circ} \mathrm{C} / \mathrm{min}$. The shear rate $(\gamma)$, shear stress $(\tau)$, and viscosity $(\eta)$ were calculated using the Margules equation [61]. The dynamic viscosity ( $\left.\eta^{\prime}\right)$ and elastic modulus (G') were calculated using a modification of Markovitz equation [62]. The mechanical loss tangent was calculated from the relationship $\tan \delta=\mathrm{G}$ '/G' where G" is the loss modulus ( $\left.\omega \eta^{\prime}\right)$ and $\omega$ is the angular velocity of the outer cylinder. The values reported are the means of two determinants.

\section{Results}

\subsection{Flow Characteristics}

To compare the rheological behaviors of S-198 gum to those of gellan (native and deacylated), welan, rhamsan (native and deacetylated), and S-88 gum, the viscosity and dynamic viscoelasticity were measured under the same conditions as in of our previous studies [5] [6] [51]-[54] [58]. Although the flow curves of S-198 gum approximated to shear-thinning behavior at a concentration of $0.1 \%$, they shifted to high shear stress and approximated plastic behavior above $0.3 \%$ at $25^{\circ} \mathrm{C}$, as shown in Figure 1 . The yield value of the S-198 gum solution was estimated to be $2.5,5.0$ and $12.0 \mathrm{~Pa}$ at $0.3 \%, 0.5 \%$ and $0.8 \%$, respectively. The result indicates that secondary associations within and/or between molecules occur for the S-198 gum solutions above 0.3\% [5] [6] [51]-[54] [58]. The flow curves of S-198 gum solutions shifted in proportion to the concentrations. The tendency essentially agreed with that of welan [51], rhamsan [52] [53], S-657 [54] and S-88 [58] gum, but differed from that of gellan (deacylated) gum [5], where the flow curves shifted to a very low shear-stress below $0.9 \%$ and exhibited Newtonian behavior. This might be caused by the breakdown of an intermolecular association for gellan gum, under a shear-rate of $9.50 \mathrm{~s}^{-1}$, as the $1.0 \%$ solution exhibited a very high shear-stress and exhibited plastic behavior, the yield value of which was estimated to be $1.0 \mathrm{~Pa}[5]$.

\subsection{Viscosity}

Figure 2 shows the effect of temperature on the viscosity of S-198 gum at various concentrations. A slight decrease in viscosity was observed for a solution of $0.1 \%$ with increasing temperature up to $50^{\circ} \mathrm{C}$, which was considered to be a transition temperature, and then remained constant with further increases in temperature except for a slight increase above $70^{\circ} \mathrm{C}$. The behavior at the transition temperature indicates that secondary associations

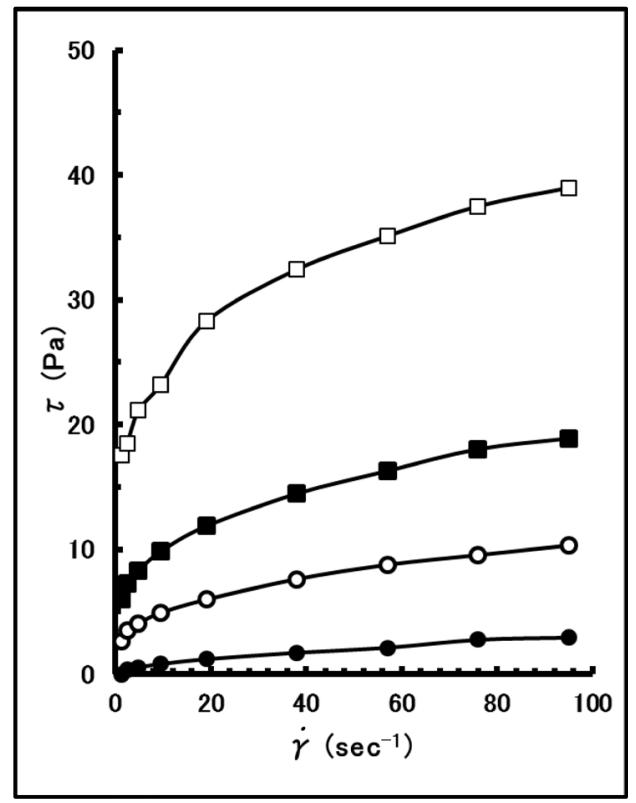

Figure 1. Flow curves of various concentrations of S-198 gum at $25^{\circ} \mathrm{C}$. 


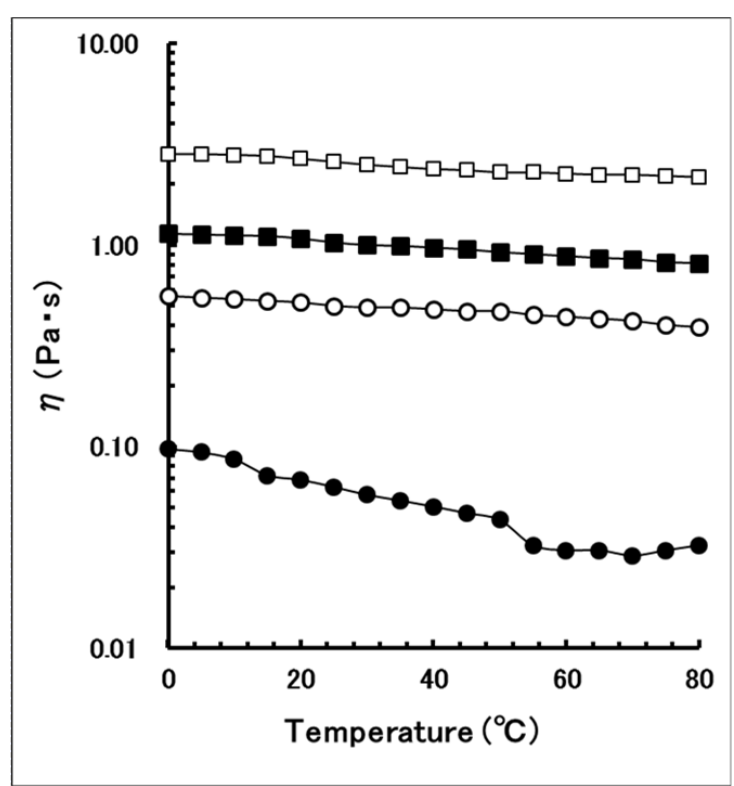

Figure 2. Effect of temperature on the viscosity of S-198 gum at various concentrations.

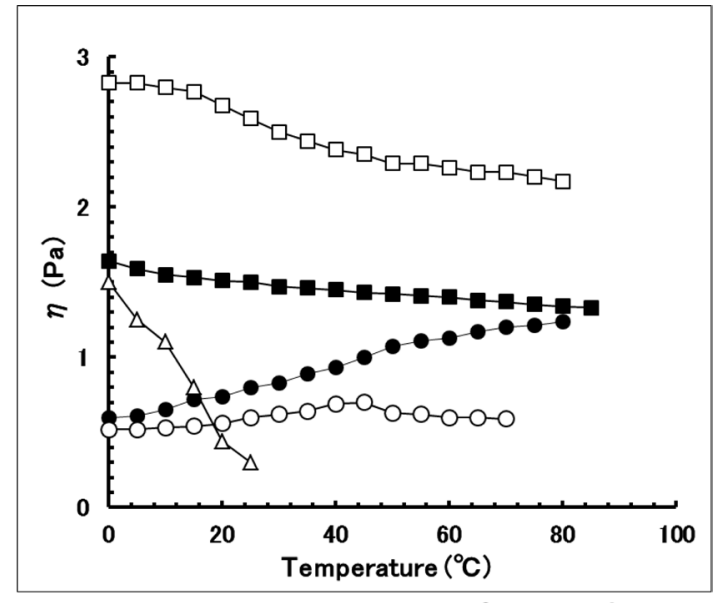

Symbols: $\square, \mathrm{S}-198$ gum; $\triangle$, gellan gum; $\mathbf{\square}$, welan gum; •, S-657 gum; O, S-88 gum.

Figure 3. Effect of temperature on the viscosity of S-198, gellan, welan, S-657 and S-88 gums at $0.8 \%$ and $9.5 \mathrm{~s}^{-1}$.

dissociate above this temperature. In a $0.1 \%$ solution, hydrogen bonding seemed to dissociate above $50^{\circ} \mathrm{C}$ [9], and hydrophobic interactions might occur above $70^{\circ} \mathrm{C}$, as a similar phenomenon was observed in curdlan, $\beta$-1,3-glucan, solution [9]. The viscosity for $0.3 \%, 0.5 \%$ and $0.8 \%$ solutions remained constant with increasing temperature up to $80^{\circ} \mathrm{C}$. The results indicate that S-198 gum molecules exhibit thermostable viscosity.

The effect of temperature on the viscosity of S-198, deacylated gellan, welan, S-657 and S-88 gum at a concentration of $0.8 \%$ is shown in Figure 3 . Alhough the viscosity of gellan gum was slightly high at a low temperature $\left(0^{\circ} \mathrm{C}\right)$, it decreased rapidly with increasing temperature. The decrease in the viscosity is due to dissociation of intermolecular associations. In contrast, the branched S-198, welan, S-657 and S-88 gum samples exhibited quite different viscosity properties. The viscosity of welan decreased slightly with increasing temperature, but remained high even at $85^{\circ} \mathrm{C}$. S-198 gum showed the highest value and remained constant with increasing temperature up to $15^{\circ} \mathrm{C}$, which was considered to be the first transition temperature, decreased slightly with further increases in temperature up to $45^{\circ} \mathrm{C}$, which was considered to be the second transition temperature, and remained constant with further increases in temperature. This phenomenon is attributed to a slight dissociation of the secondary associations above the first transition temperature $\left(15^{\circ} \mathrm{C}\right)$, and the formation of additional associations above the second transition temperature $\left(45^{\circ} \mathrm{C}\right)$. The viscosity of S-657 and S-88 gum remained low at low 
a temperature $\left(0^{\circ} \mathrm{C}\right)$ but increased gradually with increasing temperature up to $45^{\circ} \mathrm{C}$ and $50^{\circ} \mathrm{C}$, which was considered to be a transition temperature. With further increases in temperature, the viscosity of S-657 gum increased slightly, whereas that of S-88 gum decreased slightly. The increase in the viscosity was caused by an increase in the kinetic energy on the side-chains of both polysaccharides involved in the intramolecular associations. The transition temperature at $45^{\circ} \mathrm{C}$ and $50^{\circ} \mathrm{C}$ corresponds to the partial dissociation of the intramolecular association of both molecules.

As reported in preceding papers, the viscosity of native xanthan produced a sigmoidal curve [13] [18] in which it decreased slightly with increasing temperature up to $20^{\circ} \mathrm{C}$, increased gradually to a maximum at $45^{\circ} \mathrm{C}$, and then decreased slightly, but remained high even at $80^{\circ} \mathrm{C}$. In contrast, the viscosity of deacetylated [14], depyruvated [16] and deacylated [17] [18] xanthan remained constant with increasing temperature. This thermal stability was attributed formation of intramolecular associations (to which the methyl group of the acetyl residues and $\mathrm{OH}-3$ of the D-glucosyl residues contributed) and an increase in the kinetic energy of the trisaccharide side-chains of xanthan. Specifically, the viscosity of deacylated xanthan remained constant up to $25^{\circ} \mathrm{C}, 35^{\circ} \mathrm{C}$ and $40^{\circ} \mathrm{C}$ at concentrations of $0.5 \%, 0.8 \%$ and $1.0 \%$, respectively, after which it decreased rapidly [17] [18]. The rapid decrease in viscosity was attributed to free from acetyl and pyruvate groups. Accordingly, the increase in viscosity with increasing temperature of the rhamsan, S-657 and S-88 gum may be due to formation of a secondary association and an increase in the kinetic energy of the side chains. These results suggest that S-198 gum molecules may involve an intramolecular association to which the methyl groups of the L-rhamnosyl residues contribute, as the thermostability might be attributed to the presence of a methyl group in xanthan [17] [18], welan [51], rhamsan [52] [53], S-657 [54], and S-88 [58] gum.

\subsection{Elastic Modulus}

As reported previously, the elastic modulus of gellan (deacylated) gum solution was very high at a concentration of $0.8 \%$ at low temperature $\left(0^{\circ} \mathrm{C}\right)$, but decreased rapidly with increasing temperature [5]. In contrast, the elastic modulus of welan [51], rhamsan [52] [53], S-657 [54] and S-88 [58] gums remained high during the increase in temperature up to $80^{\circ} \mathrm{C}$. As shown in Figure 4, the elastic modulus of S-198 gum remained very low, even at low temperature $\left(0^{\circ} \mathrm{C}\right)$, and decreased slightly with increasing temperature at a concentration of $0.1 \%$. The elastic modulus of the $0.3 \%$ solution was approximately 50 times greater than that of the $0.1 \%$ solution and remained constant with increasing temperature. The elastic modulus increased in proportion to the concentration for $0.5 \%$ and $0.8 \%$ solutions and remained constant as the temperature increased. This phenomenon, a constantly high elastic modulus at high temperature, is in agreement with the behavior of welan, rhamsan, S-657 and S-88 gums. The $\tan \delta$ value was high (2.4) for a concentration of $0.1 \%$, indicating that a weak secondary association is involved. For the $0.3 \%$ solution, $\tan \delta$ is low $(0.48)$ at low temperature $\left(0^{\circ} \mathrm{C}\right)$ and decreased gradually with increasing temperature reaching 0.23 at $80^{\circ} \mathrm{C}$. Almost the same $\tan \delta$ was observed in a $0.5 \%$ solution (0.45) as in the $0.3 \%$, and this value increased with increasing temperature reaching 0.76 at $80^{\circ} \mathrm{C}$. Although a lower

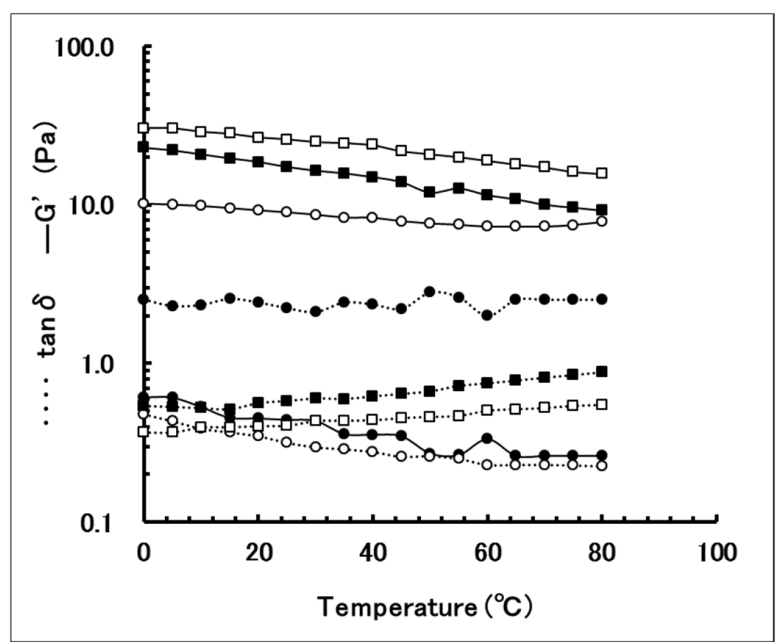

Figure 4. Effect of temperature on the elastic modulus and $\tan \delta$ of S-198 gum at various concentrations. 
$\tan \delta$ was observed in $0.8 \%$ solution (0.35) relative to $0.5 \%$ solution, it also increased gradually reaching 0.54 at $80^{\circ} \mathrm{C}$. The $\tan \delta$ values for S-198 gum (0.48 at $0.3 \%$ to 0.35 at $\left.0.8 \%\right)$ are essentially in agreement with those of welan $(0.56-0.45)$, rhamsan $(0.3-0.2)$, S-657 (0.5 - 0.4) and S-88 (0.6 - 0.2). The results suggest that a thermally stable secondary association of S-198 gum molecules is essentially attributed to intramolecular associations.

Alhough the elastic modulus of S-198 gum (0.2\%) decreased with the addition of $\mathrm{CaCl}_{2}(6.8 \mathrm{mM})$, as shown in Figure 5, a dramatic increase in the elastic modulus of gellan gum, reaching approximately 670 times (54 Pa) that in its aqueous solution $(0.08 \mathrm{~Pa})$ was observed in the $0.2 \%$ solution with the addition of $\mathrm{CaCl}_{2}(6.8 \mathrm{mM})$ at low temperature $\left(0^{\circ} \mathrm{C}\right)$. The elastic modulus increased slightly with increasing temperature up to $80^{\circ} \mathrm{C}$, which was considered to be a transition temperature, then decreased rapidly. The behavior indicates that gellan gum tightly binds $\mathrm{Ca}^{2+}$ with the carboxyl groups of the D-glucuronosyl residues contributing to cation-bridges between the different molecules with ionic bonding as a very low elastic modulus was observed in a solution of the polysaccharide alone [5]. The decrease in elastic modulus for S-198 gum with the addition of $6.8 \mathrm{mM} \mathrm{CaCl}_{2}$ may be caused by the prevention of the formation of $\mathrm{Ca}^{2+}$ bridges by the side-chains L-rhamnose of S-198 gum. A similar decrease in the elastic modulus was also observed in welan and S-88 gum solution with the addition of $\mathrm{CaCl}_{2}$. On the other hand, the elastic moduli of rhamsan and S-657 gum as a function of temperature were almost identical to that of the solution of the polysaccharide alone. These finding also indicate that the side-chains of welan, S-657 and S-88 prevent the formation of $\mathrm{Ca}^{2+}$ bridges on the carboxyl groups of the D-glucuronosyl residues between different molecules. As mentioned above, although the elastic modulus of deacetylated rhamsan gum increased upon the addition of $\mathrm{CaCl}_{2}$, an almost identical elastic modulus was observed in native rhamsan gum solution ${ }^{10}$ with increasing temperature.

The elastic modulus of S-198 gum decreased with the addition of urea (4.0 M), but remained high as the temperature increased. The result indicates that hydrogen bonding occurs in the formation of secondary associations of S-198 gum molecules to some extent. The elastic modulus remaining high even after the addition of urea indicates another secondary association in S-198 molecules. In contrast, the elastic modulus of gellan gum increased with the addition of urea $(4.0 \mathrm{M})$ at low temperature $\left(0^{\circ} \mathrm{C}\right)$ and decreased gradually with increasing temperature up to $15^{\circ} \mathrm{C}$, which was considered to be a transition temperature, after which it decreased rapidly.

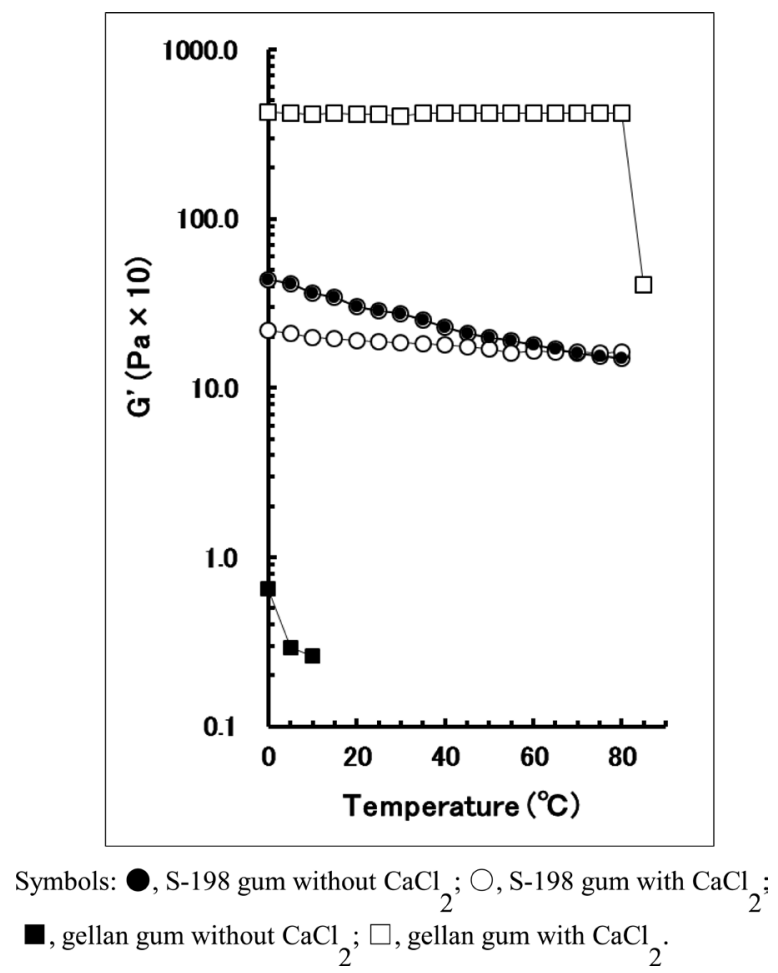

Figure 5. Effect of temperature on the elastic modulus of S-198 gum at a concentration of $0.2 \%$ with the addition of $\mathrm{CaCl}_{2}(6.8 \mathrm{mM})$. 
The transition temperature for the elastic modulus of gellan gum indicates that a secondary association is involved and that it dissociates above the temperature even in the presence of urea. The result suggests that a hydrophobic interaction participates in the interaction, as urea is known to disrupt hydrogen bonding [4] [7] [8] [31]-[33]. A slight decrease in the elastic modulus was observed for welan, rhamsan, S-657 and S-88 gums upon the addition of urea $(4.0 \mathrm{M})$, but the values remained high as the temperature increased.

\section{Discussion}

Although the primary structure of S-198 gum [60] is similar to that of gellan [43] [44], welan [55], rhamsan [56], S-657 [57] and S-88 [59] gum, its rheological characteristics differ from gellan (deacylated) [5], native gellan [6] and deacetylated rhamsan [12], but are essentially in agreement with those of welan [51], native rhamsan [52] [53], S-657 [54] and S-88 [58] gums. Thus, S-198 gum molecules may involve intramolecular associations, as do welan, rhamsan, S-657 and S-88 gum molecules. We propose intramolecular associations of S-198 gum molecules in aqueous solution, as illustrated in Scheme 8. The intramolecular associations may occur between the methyl group of the L-rhamnosyl residue which adopts a ${ }^{1} \mathrm{C}_{4}$-pyranose ring conformation, and the adjacent hemiacetal oxygen atom of the D-glucosyl residue with van der Waals forces of attraction and between C-4 of the hydroxyl group of the L-mannosyl residue, which adopts a ${ }^{1} \mathrm{C}_{4}$-pyranose ring conformation and the adjacent hemiacetal oxygen atom of the D-glucosyl residue with hydrogen bonding to make the polymer molecules rigid. The intramolecular associations play a dominant role in the thermostability of S-198 gum aqueous solutions.

The structures of S-198 and S-88 gums are quite similar, differing only in the substitution of the L-rhamnosyl side-chain at C-4 of D-glucosyl residue next to the L-rhamnosyl or L-mannosyl residue for the former and at C-3 of D-glucosyl next to D-glucuronosyl residue. In Figure 6, the elastic modulus of the S-198 solution remained a little low upon the addition of urea (4.0 M), where the thermal stability has been attributed to the intramolecular van der Waals forces of attraction, because of the dissociation of hydrogen bond. Thus, the high viscosity and elastic modulus of $0.8 \%$ S-198 gum, which is the highest among the gellan family of polysaccharides in aqueous solution should be caused by a small number (approximately half) of intramolecular associations beyond those of welan, rhamsan, S-657 and S-88 gum as illustrated in Scheme 8, Scheme 2, Scheme 3, Scheme 4 and Scheme 5 .

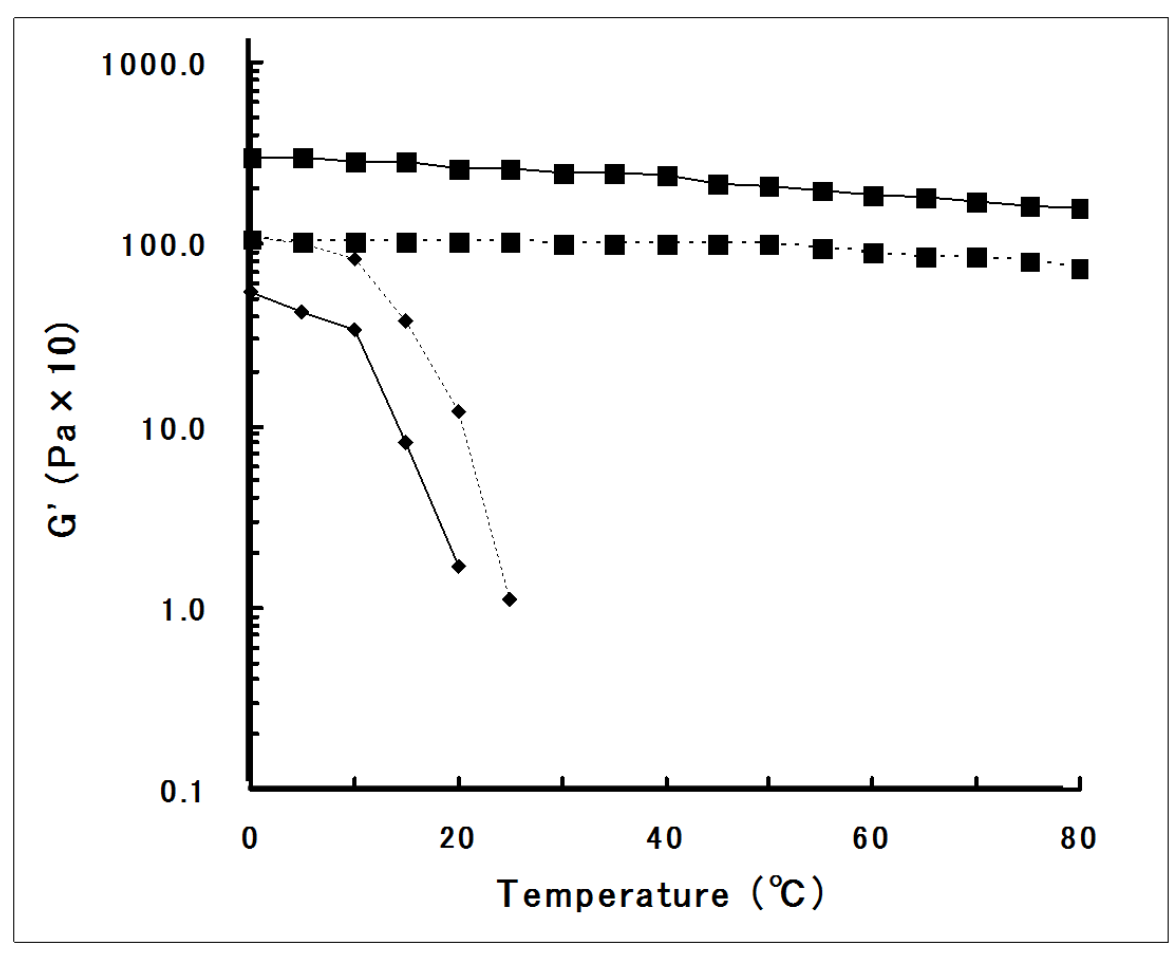

Figure 6. Effect of temperature on the elastic modulus of S-198 gum at a concentration of $0.3 \%$ with the addition of urea $(4 \mathrm{M})$. 


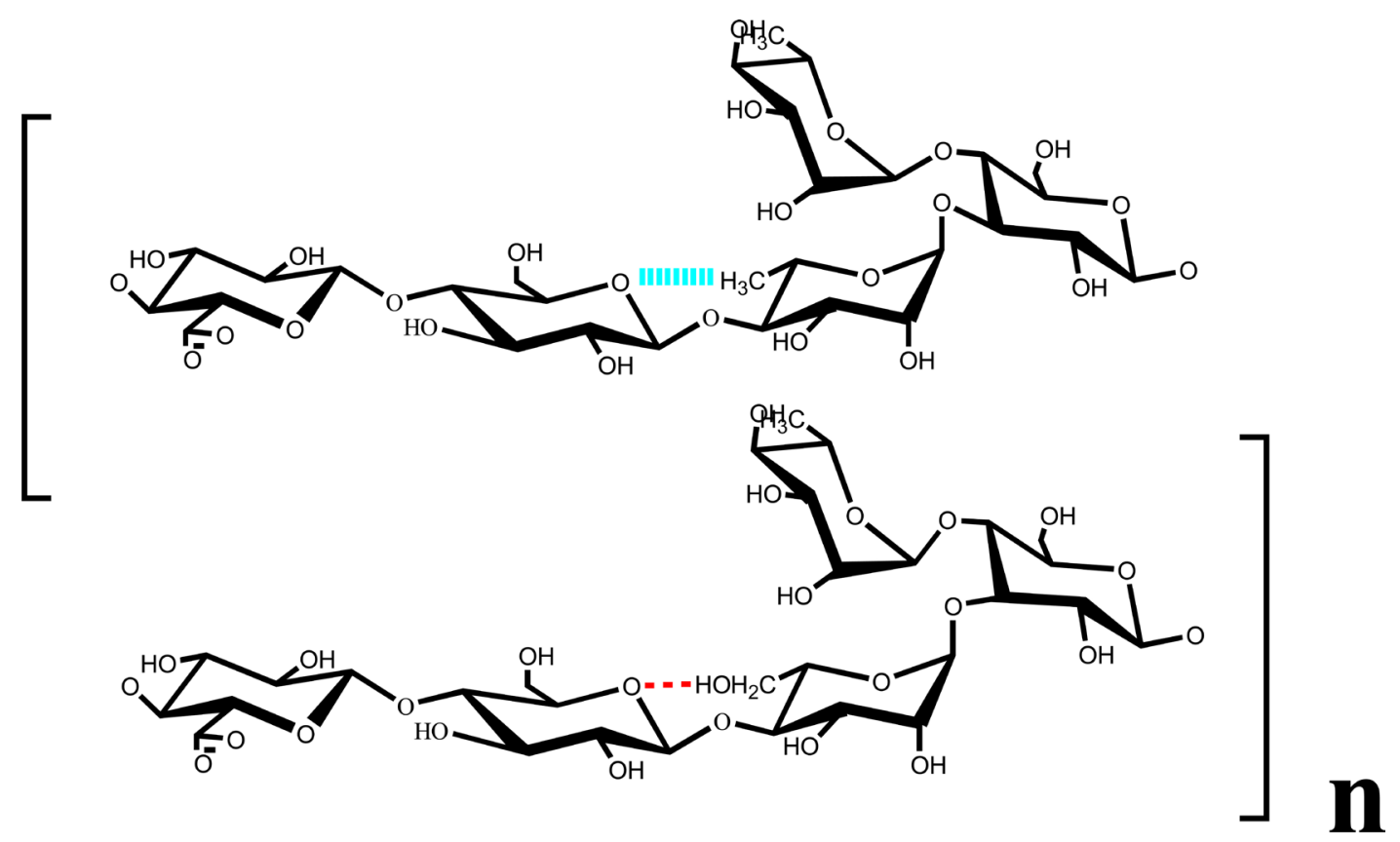

Associations; . . . , , hydrogen bonding;

Scheme 8. Proposed intramolecular associations of S-198 gum in aqueous solution.

In our proceeding papers, we investigated the molecular origin of the rheological characteristics of the gellan family of polysaccharides in aqueous solutions. Under suitable conditions, the native gellan formed weak elastic gels, whereas it forms stiff, brittle gels upon deacylation. The weak gel for native gellan gum was partially caused by the ${ }^{1} \mathrm{C}_{4}$-pyranose ring conformation of L-rhamnosyl residues, where the methyl groups were oriented in the equatorial conformation, resulting in the formation of intramolecular associations. The ${ }^{1} \mathrm{C}_{4}$-pyranose ring conformation of L-rhamnosyl residues also played a role in native rhamsan gum molecules [12] [52] [53]. The conformational changes of the L-rhamnosyl residues on the native gellan and rhamsan gum molecules from ${ }^{1} \mathrm{C}_{4}$ to ${ }^{4} \mathrm{C}_{1}$ occurred via deacylation and deacetylation resulted in the formation of gel [5] [6] [12]. Such conformational change was confirmed by ${ }^{1} \mathrm{H}-\mathrm{NMR}$ spectroscopy [6] [12].

\section{Conclusions}

Thus, the associations depicted in Scheme 8 provide explanations for not only the rheological characteristics of native and deacylated gellan gum, but also those of welan, native rhamsan, deacetylated rhamsan, S-657 and S-88 gum in aqueous solutions.

It is revealed that the L-rhamnosyl residue plays dominant role not only in gel-formation process of gellan (native [6] and deacylated [5]) and deacetylated rhamsan [12] gum, but also in thermostable properties of S-198, welan [51], rhansan [52] [53], S-657 [54] and S-88 [58] gum in aqueous media. Although many investigations have investigated the gelling and thermostable characteristics of the gellan family of polysaccharides to elucidate the structure-function relationship, no other researchers have established the mechanism at the molecular level. There is reasonable consistency in our investigations. Thus, rheological analysis is an important method for understanding the structure-function relationship of polysaccharides at molecular level in aqueous media [36]-[38].

\section{Acknowledgements}

The authors wish to express their sincere thanks to the late Professor Bengt Lindberg, at the Department of Organic Chemistry, Arrhenius Laboratory, University of Stockholm, Sweden for his valuable suggestions concerning this investigation. The authors also thank Dr. J. Baird and T. A. Talashek, CP-Kelco, California, U.S.A. for providing the gellan family of polysaccharides. 


\section{References}

[1] Tako, M. and Nakamura, S. (1986) Indicative Evidence for a Conformational Transition in $\kappa$-Carrageenan from Studies of Viscosity-Shear Rate Dependence. Carbohydrate Research, 155, 200-205. http://dx.doi.org/10.1016/S0008-6215(00)90146-0

[2] Tako, M. and Nakamura, S. (1986) Synergistic Interaction between Kappa-Carrageenan and Locust-Bean Gum in Aqueous Media. Agricultural and Biological Chemistry, 50, 2817-2822.

[3] Tako, M., Nakamura, S. and Kohda, Y. (1987) Indicative Evidence for a Conformational Transition in $l$-Carrageenan. Carbohydrate Research, 161, 247-253. http://dx.doi.org/10.1016/S0008-6215(00)90081-8

[4] Tako, M. and Nakamura, S. (1988) Gelation Mechanism of Agarose. Carbohydrate Research, 180, $277-283$. http://dx.doi.org/10.1016/0008-6215(88)80084-3

[5] Tako, M., Sakae, A. and Nakamura, S. (1989) Rheological Properties of Gellan Gum in Aqueous Media. Agricultural and Biological Chemistry, 53, 771-776.

[6] Tako, M., Teruya, T., Tamaki, Y. and Konishi, T. (2009) Molecular Origin for Rheological Characteristics of Native Gellan Gum. Colloid and Polymer Science, 287, 1445-1454. http://dx.doi.org/10.1007/s00396-009-2112-2

[7] Tako, M. and Hizukuri, S. (1995) Evidence for Conformational Transitions in Amylose. Journal of Carbohydrate Chemistry, 14, 613-622. http://dx.doi.org/10.1080/07328309508005362

[8] Tamaki, Y., Konishi, T. and Tako, M. (2011) Gelation and Retrogradation Mechanism of Wheat Amylose. Materials, 4, 1763-1775. http://dx.doi.org/10.3390/ma4101763

[9] Tako, M. and Hanashiro, I. (1997) Evidence for a Conformational Transition in Curdlan. Polymmer Gels and Networks, 5, 241-250. http://dx.doi.org/10.1016/S0966-7822(96)00036-6

[10] Tako, M. and Kohda, Y. (1997) Calcium Induced Association Characteristics of Alginate. Journal of Applied Glycoscience, 44, 153-159.

[11] Teruya, T., Tamaki, Y., Konishi, T. and Tako, M. (2010) Rheological Characteristics of Alginate Isolated from Commercially Cultured Nemacystus decipins. Journal of Applied Glycoscience, 57, 7-12. http://dx.doi.org/10.5458/jag.57.7

[12] Tako, M., Tohma, S., Taira, T. and Ishihara, M. (2003) Gelation Mechanism of Deacetylated Rhamsan Gum. Carbohydrate Polymers, 54, 279-285. http://dx.doi.org/10.1016/S0144-8617(03)00029-8

[13] Tako, M., Nagahama, T. and Nomura, D. (1977) Non-Newtonian Behavior and Dynamic Viscoelasticity of Xanthan Gum. Nippon Nogeikagaku Kaishi, 51, 513-517. http://dx.doi.org/10.1271/nogeikagaku1924.51.8_513

[14] Tako, M. and Nakamur, S. (1984) Rheological Properties of Deacetylated Xanthan Gum in Aqueous Media. Agricultural and Biological Chemistry, 48, 2987-2993.

[15] Tako, M. and Nakamura, S. (1987) Rheological Properties of Ca Salt of Xanthan Gum in Aqueous Media. Agricultural and Biological Chemistry, 51, 2919-2923. http://dx.doi.org/10.1271/bbb1961.51.2919

[16] Tako, M. and Nakamura, S. (1988) Rheological Properties of Depyruvated Xanthan Gum in Aqueous Media. Agricultural and Biological Chemistry, 52, 1585-1586. http://dx.doi.org/10.1271/bbb1961.52.1585

[17] Tako, M. and Nakamura, S. (1989) Evidence for Intramolecular Associations in Xanthan Gum in Aqueous Media. Agricultural and Biological Chemistry, 53, 1941-1946.

[18] Tako, M. (1992) Molecular Origin for Rheological Characteristics of Xanthan Gum. ACS Symposium Series, 489, 268-281. http://dx.doi.org/10.1021/bk-1992-0489.ch017

[19] Tako, M., Asato, A. and Nakamura, S. (1984) Rheological Aspects of the Intermolecular Interaction between Xanthan and Locust Bean Gum in Aqueous Media. Agricultural and Biological Chemistry, 48, 2995-3000.

[20] Tako, M., Asato, A. and Nakamura, S. (1986) D-Mannose-Specific Interaction between Xanthan and D-GalactoD-Mannan., 204, 33-36. http://dx.doi.org/10.1016/0014-5793(86)81382-5

[21] Tako, M. (1991) Synergistic Interaction between Deacylated Xanthan and Galactomannan. Journal of Carbohydrate Chemistry, 10, 619-633. http://dx.doi.org/10.1080/07328309108543936

[22] Tako, M. and Nakamura, S. (1985) Synergistic Interaction between Xanthan and Guar Gum. Carbohydrate Research, 138, 207-213. http://dx.doi.org/10.1016/0008-6215(85)85104-1

[23] Tako, M. (1991) Synergisic Interaction between Xanthan and Tara-Bean Gum. Carbohydrate Polymers, 16, $239-252$. http://dx.doi.org/10.1016/0144-8617(91)90111-O

[24] Pakdee, P., Tako, M., Yokohari, T., Kinjyo, K., Hongo, F. and Yaga, S. (1995) Synergistic Interaction between Xanthan and Galactomannan Isolated from Leucaena leucocephala de WIT. Journal of Applied Glycoscience, 42, 105-113.

[25] Tako, M., Teruya, T., Tamaki, Y and Ohkawa, K. (2010) Co-Gelation Mechanism of Xanthan and Galactomannan. Colloid and Polymer Science, 288, 1161-1166. http://dx.doi.org/10.1007/s00396-010-2242-6 
[26] Tako, M. (1992) Synergistic Interaction between Xanthan and Konjac Glucomannan in Aqueous Media. Bioscience, Biotechnology, and Biochemistry, 56,1188-1192 http://dx.doi.org/10.1271/bbb.56.1188

[27] Tako, M. (1993) Binding Sites for D-Mannose-Specific Interaction between Xanthan and Galactomannan, and Glucomannan. Colloids and Surfaces B: Biointerfaces, 1, 125-131. http://dx.doi.org/10.1016/0927-7765(93)80043-X

[28] Tako, M., Qi, Z.Q., Yoza, E. and Toyama, S. (1998) Synergistic Interaction between k-Carrageenan Isolated from Hypnea charoides $\mathrm{L}_{\text {LAmouroux }}$ and Galactomannan on Its Gelation. Food Research Internal, 31, 543-548. http://dx.doi.org/10.1016/S0963-9969(99)00022-8

[29] Tako, M. and Nakamura, S. (1988) Synergistic Interaction between Agarose and D-Galacto-D-Mannan in Aqueous Media. Agricultural and Biological Chemistry, 52, 1071-1072. http://dx.doi.org/10.1271/bbb1961.52.1071

[30] Tako, M. and Hizukuri, S. (1999) Gelatinization Mechanism of Rice Starch. Journal of Carbohydrate Chemistry, 18, 573-584. http://dx.doi.org/10.1080/07328309908544020

[31] Tako, M. (2000) Gelatinization Characteristics of Rice Starch (Yukihikari). Journal of Applied Glycoscience, 47, 187-192. http://dx.doi.org/10.5458/jag.47.187

[32] Tako, M. and Hizukuri, S. (2000) Retrogradation Mechanism of Rice Starch. Cereal Chemistry, 77, 473-477. http://dx.doi.org/10.1094/CCHEM.2000.77.4.473

[33] Tako, M. and Hizukuri, S. (2003) Gelatinization Mechanism of Potato Starch. Carbohydrate Polymers, 48, 397-401. http://dx.doi.org/10.1016/S0144-8617(01)00287-9

[34] Tako, M., Tamaki, Y., Konishi, T., Shibanuma, K., Hanashiro, I. and Takeda, Y. (2008) Gelatinization and Retrogradation Characteristics of Wheat (Rosella) Starch. Food Research International, 41, 797-802. http://dx.doi.org/10.1016/j.foodres.2008.07.002

[35] Tako, M., Tamaki, Y., Teruya, T., Konishi, T., Shibanuma, K., Hanashiro, I. and Takeda, Y. (2009) Rheological Characteristics of Halberd Wheat Starch. Starch, 61, 275-281. http://dx.doi.org/10.1002/star.200800073

[36] Tako, M. (2000) Structural Principles of Polysaccharide Gels. Journal of Applied Glycoscience, 47, 49-53. http://dx.doi.org/10.5458/jag.47.49

[37] Tako, M. (2015) The Principle of Polysaccharide Gels. Advances in Bioscience and Biotechnology, 6, 22-36. http://dx.doi.org/10.4236/abb.2015.61004

[38] Tako, M., Tamaki, Y., Teruya, T. and Takeda, Y. (2014) The Principles of Starch Gelatinization and Retrogradation. Food and Nutrition Sciences, 5, 280-291. http://dx.doi.org/10.4236/fns.2014.53035

[39] Kang, K.S., Veeder, G.T., Mirrasoul, P.J., Kaneko, T. and Cottrell, I.W. (1982) Agar-Like Polysaccharide Produced by a Pseudomonas Species: Production and Basic Properties. Applied and Environmental Microbiology, 43, $1086-1091$.

[40] Sandford, P.A., Cottrell, I.W. and Pettitt, D.J. (1984) Microbial Polysaccharides: New Products and Their Commercial Applications. Pure and Applied Chemistry, 56, 879-892. http://dx.doi.org/10.1351/pac198456070879

[41] Osmalek, T., Froelich, A. and Tasarek, S. (2014) Application of Gellan Gum in Pharmacy and Medicine. International Journal of Pharmaceutics, 466, 328-340. http://dx.doi.org/10.1016/j.ijpharm.2014.03.038

[42] Moxon, S.R. and Smith, A.M. (2016) Controlling the Rheology of Gellan Gum Hydrogels in Cell Culture. International Journal of Biological Macromolecules, 84, 79-86. http://dx.doi.org/10.1016/j.ijbiomac.2015.12.007

[43] O’Neill, M.A., Selvendran, R.R. and Morris, V.J. (1983) Structure of the Acidic Extracellular Gelling Polysaccharide Produced by Pseudomonas elodea. Carbohydrate Research, 124, 123-133. http://dx.doi.org/10.1016/0008-6215(83)88360-8

[44] Jansson, P.E., Lindberg, B. and Sandford, P.A. (1983) Structural Studies of Gellan Gum, an Extracellular Polysaccharide Elaborated by Pseudomonas elodea. Carbohydrate Research, 124, 135-139. http://dx.doi.org/10.1016/0008-6215(83)88361-X

[45] Kuo, M.S., Mort, A.J. and Dell, A. (1986) Identification and Location of L-Glycerate, an Unusual Acyl Substituent in Gellan Gum. Carbohydrate Research, 156, 173-187. http://dx.doi.org/10.1016/S0008-6215(00)90109-5

[46] Upstill, C., Atkins, E.D.T. and Attwool, P.T. (1986) Helical Conformation of Gellan Gum. International Journal of Biological Macromolecules, 8, 275-288. http://dx.doi.org/10.1016/0141-8130(86)90041-3

[47] Grasdalen, H. and Smidsrød, O. (1987) Gelation of Gellan Gum. Carbohydrate Polymers, 7, 371-393. http://dx.doi.org/10.1016/0144-8617(87)90004-X

[48] Chandrasekaran, R., Pulgjaner, L.C., Joyce, K. and Arnott, S. (1988) Cation Interaction in Gellan: An X-Ray Study of the Potassium Salt. Carbohydrate Research, 181, 23-40. http://dx.doi.org/10.1016/0008-6215(88)84020-5

[49] Lee, E.J. and Chandrasekaran, R. (1991) X-Ray and Computer Modeling Studies on Gellan-Related Polymers: Molecular Structures of Welan, S-657, and Rhamsan. Carbohydrate Research, 214, 11-24.

http://dx.doi.org/10.1016/S0008-6215(00)90526-3 
[50] Morris, E.R., Gothard, M.G.E., Hember, M.W.N., Manning, C.E. and Robinson, G. (1996) Conformation and Rheological Transition of Welan, Rhamsan and Acylated Gellan. Carbohydrate Polymers, 30, 165-175. http://dx.doi.org/10.1016/S0144-8617(96)00059-8

[51] Tako, M. and Kiriaki, M. (1990) Rheological Properties of Welan Gum in Aqueous Media. Agricultural and Biological Chemistry, 54, 3079-3084.

[52] Tako, M. (1993) Molecular Origin for Thermal Stability of Rhamsan Gum in Aquesou Media. Bioscience, Biotechnology, and Biochemistry, 57, 1182-1184. http://dx.doi.org/10.1271/bbb.57.1182

[53] Tako, M. (1993) Molecular Origin for Thermal Stability of Welan and Rhamsan Gum. In: Yalpani, M., Ed., Carbohydrates and Carbohydrate Polymers, ATL Press, Mount Prospect, 206-215.

[54] Tako, M. (1994) Molecular Origin for the Thermal Stability of S-657 Polysaccharide Produced by Xanthomonas ATCC 53159. Polymer Gels and Network, 2, 91-104. http://dx.doi.org/10.1016/0966-7822(94)90029-9

[55] Jansson, P.E., Lindberg, B., Widmalm, G. and Sandford, P.A (1985) Structural Studies of a Polysaccharide (S-130) Elaborated by Alcaligenes ATCC 31555. Carbohydrate Research, 139, 217-223. http://dx.doi.org/10.1016/0008-6215(85)90022-9

[56] Jansson, P.E., Lindberg, B., Lindberg, J., Maekawa, E. and Sandford, P.A. (1986) Structural Studies of a Polysaccharide (S-194) Elaborated by Alcaligenes ATCC 31961. Carbohydrate Research, 156, 157-163. http://dx.doi.org/10.1016/S0008-6215(00)90107-1

[57] Chowdhury, T.A., Lindberg, B., Lindquist, U. and Baird, J. (1987) Structure Studies of an Extracellular Polysaccharide, S-657, Elaborated by Xanthomonas ATCC 53159. Carbohydrate Research, 164, 117-122. http://dx.doi.org/10.1016/0008-6215(87)80124-6

[58] Tako, M. and Tamaki, H. (2005) Molecular Origin for the Thermal Stability of S-88 Gum Produced by Pseudomonas ATCC 31554. Polymer Journal, 37, 498-505. http://dx.doi.org/10.1295/polymj.37.498

[59] Jansson, P.E., Kumar, N.S. and Lindberg, B. (1986) Structural Studies of a Polysaccharide (S-88) Elaborated by Pseudomonas ATCC 31554. Carbohydrate Research, 156, 165-172. http://dx.doi.org/10.1016/S0008-6215(00)90108-3

[60] Chowdhury, T.A., Lindberg, B., Lindquist, U. and Baird, J. (1987) Structural Studies of an Extracellular Polysaccharide (S-198) Elaborated by Alcaligenes ATCC 31853. Carbohydrate Research, 161, 127-132. http://dx.doi.org/10.1016/0008-6215(87)84011-9

[61] Harris, J. (1977) Rheology and Non-Newtonian Flow. Longman, New York, 28-33.

[62] Markovitz, H. (1952) A Property of Bressel Functions and Its Application to the Theory of Two Rheometers. Journal of Applied Physics, 23, 1070-1077. http://dx.doi.org/10.1063/1.1701988 